\title{
The study of psychological characteristics of undergraduate students before and after Russian "perestroika"
}

Vladimir Uryvaev (1), Vladimir Mazilov (2), Yuri Slepko (2),

Vladlena Zolotareva (1), Olga Sysoeva (3)

1- Yaroslavl State Medical University, Yaroslavl, Russia

2 - K.D. Ushinsky Yaroslavl State Pedagogical University, Yaroslavl, Russia

3 - Far Eastern State Medical University, Khabarovsk, Russia

Goal. The current empirical study (ongoing from 1992) is aimed at analyzing the influence of the socio-political events in Russia (primarily of the "perestroika" crisis of 1985-2000) on the formation of the basic psychological characteristics of the youngsters.

Design and methods of the study. Two groups are compared. For the first participants born in 1973 - personality formation took place during "pre-perestroika" period. Testing - 1992 (150 persons). Participants of the second group - born in 1992 belong to "post-perestroika" generation. Testing - 2016 (150 persons). Both groups are composed of medical students (sophomores) from a university in central Russia.

The report gives generalized data from tree psychodiagnostical tests: 16-PF, Intelligence Structure Assessment (R. Amthauer), MMI (J. Nuttin)

Main results. The most important are two results obtainable only in the course of complex data processing (taking into account parameters of all three main psychodiagnostical tests).

First, the index of structural integration has grown considerably (almost one and a half times: from 209 for the subjects of the first group to 293 for the subjects in the second), as well as the index of structural organization (from 30 to 122, four times)

Second, the most significant changes in the index of structural integration took place for the following particular characteristics: category C (MMI test, "social motivation" quintuple growth in the second group); factor B (16 PF, "abstract thinking", triple growth in the second group), factor C (16 PF, "emotional stability" - more than quadruple growth in the second group) and more than triple growth in five parameters in Intelligence Assessment subtests ("oddball task", "search for analogies","arithmetic operations", "figure selection", "spacial perception").

Discussion. Defining parameters of behavior of the "post-perestroika" youth are primarily systemic variables uniting values from separate tests.

The main particular changes are: growing interest in social life, rationality in the regulation of behavior and intensification of intellectual development (with a slant towards "analogous" thinking).

The research have been supported by RSF grant (project N 18-18-00157)

E-mail: ladoyar@mail.ru

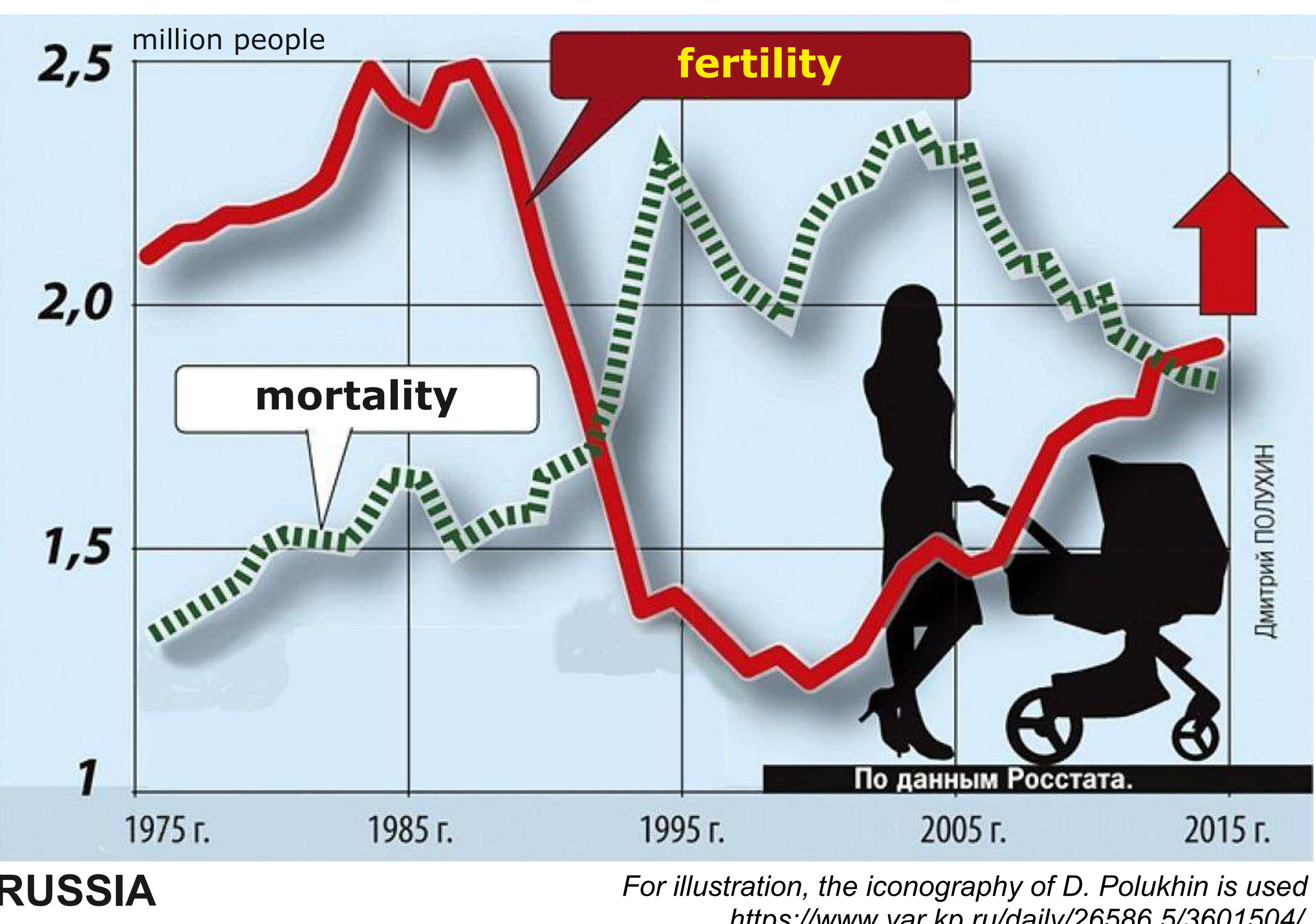

https://www yar.kp.ru/daily/26586.5/3601504/

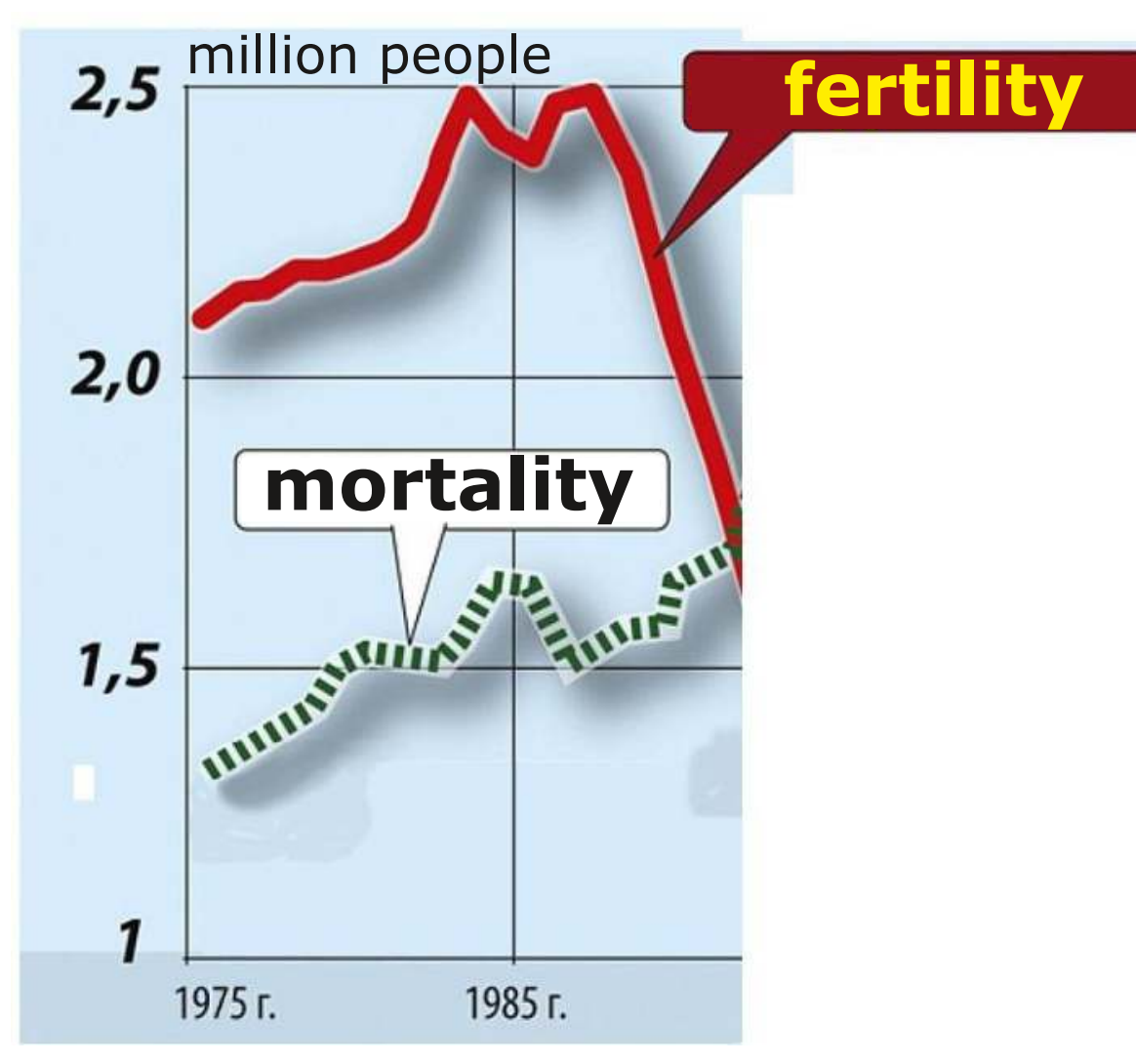

Socio-demographic background that accompanies the formation of the personality of the subjects of the first experimental group (born 1973, explained in the text).

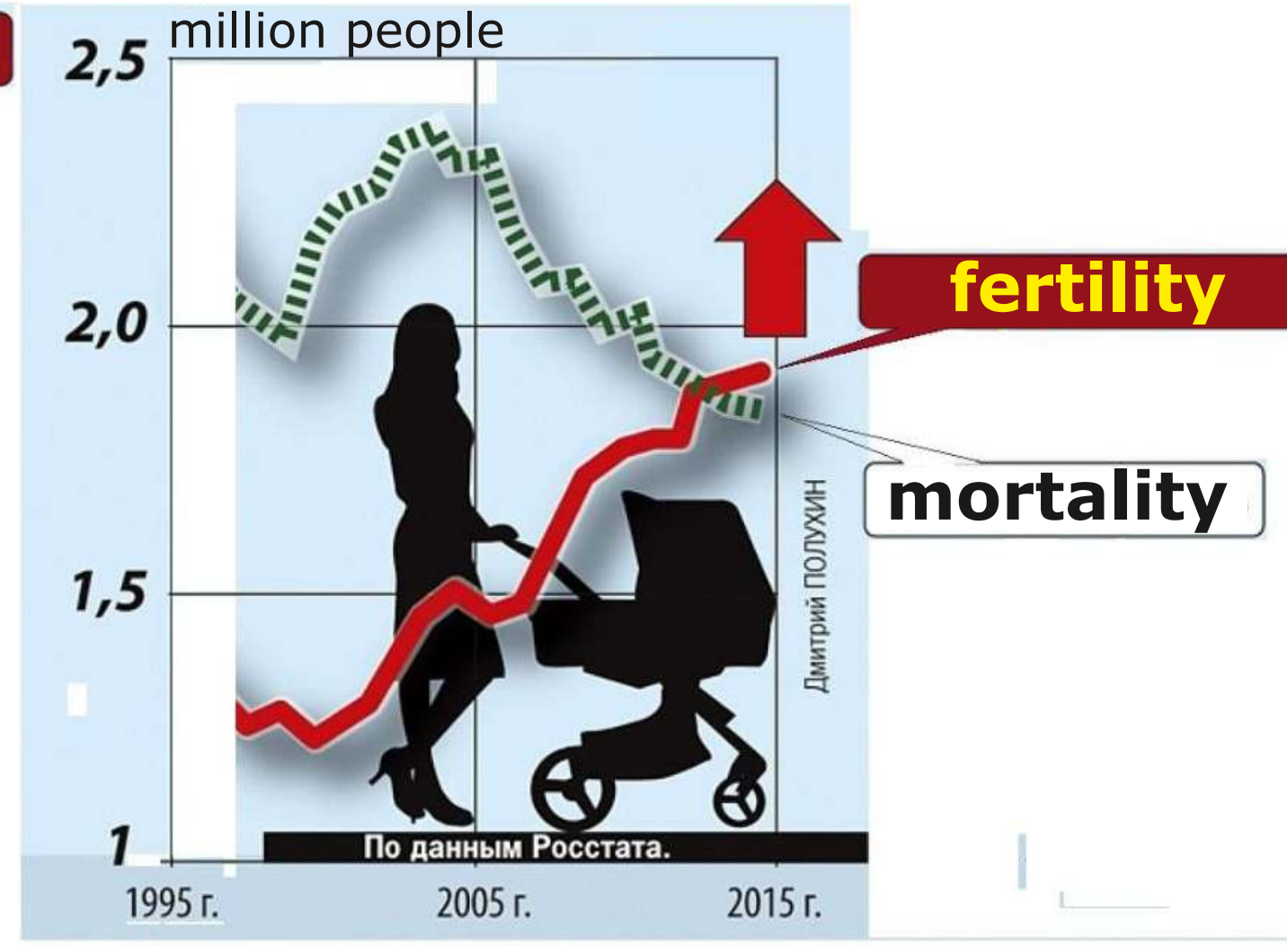

Socio-demographic background that accompanies the formation of the personality of the subjects of the second experimental group (born 1997, explained in the 